\title{
Purple non-sulfur photosynthetic bacteria monitor environmental stresses
}

\author{
Mariann Kis a, Gábor Sipka a, Emese Asztalos a, Zsolt Rázga b, Péter Maróti a, ${ }^{*}$ \\ a Department of Medical Physics, University of Szeged, Hungary \\ b Department of Pathology, University of Szeged, Hungary
}

The publisher's version: Journal of Photochemistry and Photobiology B: Biology 151 (2015) 110-117; http://dx.doi.org/10.1016/j.jphotobiol.2015.07.017

\begin{abstract}
Heavy metal ion pollution and oxygen deficiency are major environmental risks for microorganisms in aqueous habitat. The potential of purple non-sulfur photosynthetic bacteria for biomonitoring and bioremediation was assessed by investigating the photosynthetic capacity in heavy metal contaminated environments. Cultures of bacterial strains Rhodobacter sphaeroides, Rhodospirillum rubrum and Rubrivivax gelatinosus were treated with heavy metal ions in micromolar $\left(\mathrm{Hg}^{2+}\right)$, submillimolar $\left(\mathrm{Cr}^{6+}\right)$ and millimolar $\left(\mathrm{Pb}^{2+}\right)$ concentration ranges. Functional assays (flash-induced absorption changes and bacteriochlorophyll fluorescence induction) and electron micrographs were taken to specify the harmful effects of pollution and to correlate to morphological changes of the membrane. The bacterial strains and functional tests showed differentiated responses to environmental stresses, revealing that diverse mechanisms of tolerance and/or resistance are involved. The microorganisms were vulnerable to the prompt effect of $\mathrm{Pb}^{2+}$, showed weak tolerance to $\mathrm{Hg}^{2+}$ and proved to be tolerant to $\mathrm{Cr}^{6+}$. The reaction center controlled electron transfer in Rvx. gelatinosus demonstrated the highest degree of resistance against heavy metal exposure.
\end{abstract}

\section{Introduction}

Microorganisms have to face with and accommodate to several stress factors of either natural or anthropogenic origins in their environment. The scientists have the task to work out useful applications in conservation of the environment including the protection of the biodiversity of aqueous habitats [1-5] and monitor and remediation of pollution in the environment [6-8]. Metal ions of environmental contamination may constitute one of the most important factors of toxicity. Essential metal ions of low concentrations play an integral role in the life processes of microorganisms: they function as catalysts for biochemical reactions, $\mathrm{K}+$ and $\mathrm{Na}+$ are required for maintenance of osmotic balance, transition metals like iron, copper, and nickel are involved in redox processes, magnesium and zinc stabilize various enzymes and DNA through electrostatic forces and iron, magnesium, nickel, and cobalt are part of complex molecules with a wide array of functions [9]. However, metals at high concentrations are toxic to microorganisms. The consequence of the metal ion stress is the nonspecific entrapment of the metal ions by binding sites present on the cellular surface (bioadsorption) [10-12] followed by transport through the cell wall and interaction with the metabolic cycle inside the cell [13-15]. The processes are not independent. The metabolic activity reduces the bioadsorption of the metal ions due to increased competition with other cations (e.g. protons) produced by the living cells [16,17] but in several other cases the cells prove to be more efficient in heavy metal binding [18,19]. The essential metals are displaced from their native binding sites or removed from ligand interactions. Nonessential metals bind with greater affinity to thiol-containing groups and oxygen sites than do essential metals [20,21]. Toxicity results from alterations in the conformational structure of nucleic acids, proteins and intracytoplasmic membrane system and in the function of key proteins (e.g. reaction center and antenna in photosynthetic bacteria [19]) and interference with oxidative phosphorylation and osmotic balance [21]. Bacteria can adapt to excess metals through a variety of chromosomal, transposon, and plasmid-mediated resistance systems. A number of different uptake and resistance mechanisms have been identified and reviewed [22-25]. Sensitive and selective detection of toxic chemical compounds and heavy metals is of significant importance for human health and the preservation and conservation of the environment. Microbial biosensors offer considerable advantages: they allow inexpensive and facile detection without complex equipment and provide flexibility for various analyses, and pre- and/or post-processes such as purification and separation are not required (see e.g. the microbial luminescence-based biosensors [26]). Heavy metals can be tracked by various spectroscopic methods. Atomic absorption spectroscopy and inductively coupled plasma atomic emission spectroscopy, can offer high sensitivity for Pb ${ }^{2+}$ detection [27]. Recent advances in new materials, particularly in nano- and bio-materials, have opened a new era of analytical techniques. Due to their unique electronic, physical, chemical and mechanical properties, nano- and bio-materials have been explored their extensive applications in electrochemistry [28]. In addition to metal ions, transition between aerobic and anaerobic conditions may create another environmental stress to the organisms. The living cells control the level of expression and the composition of their molecular machinery according to oxygen and redox conditions. This control involves several regulatory systems. However, the chances of survival of the organism would be exposed to high risk if the oxygen partial pressure changed beyond critical levels as a consequence of contamination of physical, chemical or biological origins. For example, its functioning in high oxygen tension could lead to the formation of reactive oxygen species (ROS), in particular singlet oxygen which is highly toxic for the cell. The quality and quantity of the pollution of the habitat can be exactly determined by a broad variety of sophisticated physical and chemical methods. In some cases, however, biomonitoring systems can be used more directly and demonstratively to characterize the conditions. In this study, purple photosynthetic bacteria will be applied to monitor the properties of the aqueous habitat exposed to major environmental stresses of heavy metal ions and anaerobism. They are very versatile microorganisms and can grow under different conditions. They are capable of growth by aerobic and anaerobic respiration, fermentation, and anoxygenic photosynthesis. The intracytoplasmic membrane (ICM) in Rba. sphaeroides adapts to alterations in oxygen tension [29,30]. Due to this versatility, they provide an excellent biomonitoring system by detection of changes of both photosynthesis and membrane development [31]. They act as sponges for the heavy metals accumulated mainly in waterways as a consequence of anthropogenic activities [32,33,19]. Additionally, they have been proved as highly promising candidates for bioremediation [34]. Here, absorption and fluorescence induction of bacteriochlorophylls (BChl) and electrochromic changes of carotenoids in the photosynthetic membrane are used to track the changes of photosynthesis of bacteria exposed to different sorts of contaminations including deoxygenation and $\mathrm{Hg}^{2+}, \mathrm{Cr}^{6+}$ and $\mathrm{Pb}^{2+}$ metal ions among the most toxic and harmful chemical agents in the environment. These methods are timesaving, economical and nondestructive. The BChl fluorescence is a particularly excellent marker of bacterial photosynthesis as a label-free biosensor and has no effect on the environment. It is measured by a low-cost and portable fluorometer [35]. The techniques are sensitive and are able to detect the harmful effect of contamination in the early phase of its development. 


\section{Materials and methods}

\subsection{Bacterial strains and growth conditions}

The photosynthetic purple bacterium Rhodospirillum (Rps.) rubrum and Rubrivivax (Rvx.) gelatinosus were grown in Siström's medium [36] either in completely filled screw top vessels without oxygen (photoheterotrophic and anaerobic growth), or in half filled Erlenmeyer flasks sparged with a mixture of air and nitrogen provided by an air pump and a N2 container, respectively (photoheterotrophic and semiaerobic growth). The oxygen-to-nitrogen volumetric ratio of the gas mixture was adjusted by calibrated flow rate meters (rotameters). The oxygen tension balanced with $\mathrm{N}_{2}$ could be changed between $21 \%$ (air) and $0 \%$ (anaerobic condition). The medium was inoculated from a dense batch culture (1:100) and was illuminated by tungsten lamps that assured $13 \mathrm{~W} \mathrm{~m} 2$ irradiance on the surface of the vessel as described earlier [37]. For experiments of bleaching and induction (greening) of the ICM under aerobic and anaerobic conditions, respectively, the illuminated culture was sampled for near-IR absorption spectra and BChl fluorescence measurements.

\subsection{Chemicals}

The cells were harvested at the exponential phase of the growth and bubbled by nitrogen for 15 min before measurements. Variable amounts of $\mathrm{HgCl}_{2}\left(\mathrm{Hg}^{2+}\right), \mathrm{K}_{2} \mathrm{CrO}_{4}(\mathrm{Cr}(\mathrm{VI}))$ and $\mathrm{Pb}\left(\mathrm{CH}_{3} \mathrm{COO}\right)_{2} * 3 \mathrm{H}_{2} \mathrm{O}(\mathrm{Pb}(\mathrm{II})$-acetate) were added to the bacterial culture for heavy metal ion treatment [7]. These chemicals are highly soluble in aqueous solution under physiological conditions. $10 \mathrm{mM} \mathrm{HgCl} 2,100 \mathrm{mM} \mathrm{K} 2 \mathrm{CrO}_{4}$ and $\mathrm{Pb}\left(\mathrm{CH}_{3} \mathrm{COO}\right) 2$ $/ 3 \mathrm{H}_{2} \mathrm{O}$ stock solutions were prepared freshly before the experiment. The durations of the $\mathrm{Pb}(\mathrm{II})$-acetate, $\mathrm{K}_{2} \mathrm{CrO}_{4}$ and $\mathrm{HgCl}_{2}$ treatments were prompt, $4 \mathrm{~h}$ and $5 \mathrm{~h}$, respectively. The samples were kept illuminated under anaerobic condition during the treatment.

\subsection{Electron microscopy}

The bacteria were filtered with high grade filter paper and fixed with $4 \%$ glutaraldehyde. The specimens were embedded in Embed812 (EMS, USA) and 70-nm thin sections were prepared with an Ultracut S ultra-microtome (Leica, Austria). After staining with uranyl acetate and lead citrate, the sections were observed with a Phillips CM10 electron microscope (Eindhoven, the Netherlands) equipped with a Mega-view G2 digital camera and iTEM imaging analysis software (Olympus, Münster, Germany).

\subsection{Steady-state absorption spectroscopy}

The steady-state near infrared absorption spectra of the cells during the growth were recorded at room temperature by a single beam spectrophotometer (Thermo Spectronic Helios). The baselines were corrected for light scattering, and the spectra were decomposed into Gaussian components by least square Marquardt procedure to obtain the band area.

\subsection{Flash-induced absorption kinetics}

The kinetics of absorption changes of the whole cells induced by Xe flash were detected by a home-constructed spectrophotometer [37]. The electrochromic shift (ECS) of the carotenoids in the photosynthetic membrane were detected at $530 \mathrm{~nm}$ wavelength with reference to $510 \mathrm{~nm}$ wavelength.

\subsection{Induction of BChl fluorescence}

The induction of the BChl a fluorescence of intact cells was measured by a home built fluorimeter [35]. The light source was a laser diode (808 $\mathrm{nm}$ wavelength and $2 \mathrm{~W}$ light power) that produced rectangular shape of illumination and matched the $800 \mathrm{~nm}$ absorption band of the LH2 peripheral antenna of the cells. The BChl a fluorescence (centered at $900 \mathrm{~nm}$ in mature cells) was detected in the direction perpendicular to the actinic light beam with a near infrared sensitive, large area (diameter $10 \mathrm{~mm}$ ) and high gain Si-avalanche photodiode (APD; model 394-70-72581; Advanced Photonix, Inc., USA) protected from the scattered light of the laser by an $850 \mathrm{~nm}$ high-pass filter (RG-850).

\section{Results and discussion}

\subsection{Pollution by heavy metal ions}

As bacteria are involved in the transformation of metal compounds via metal-related bacterial metabolism, they play an important role in determination of the metal ion pathways in the environment by modifying its mobility and bioavailability, and hence its intrinsic toxicity. Several investigations of the interactions between heavy metal ions and photosynthetic microorganisms such as green algae, cyanobacteria and proteobacteria Rba. sphaeroides [38] and Rps. rubrum [39] have been reported. Below, we will deal with purple non-sulfur photosynthetic bacteria biosensing the environmental pollution caused by three heavy metal ions. Several bacterial strains, Rba. sphaeroides, Rps. rubrum and Rvx. gelatinosus that are different in membrane structures, light harvesting antenna composition and RC controlled electron transfer properties are included in the investigations. These bacteria offer the possibility of selection and construction of biosensing systems suited to various types of environmental pollution.

\subsubsection{Mercury(II) ion}

Mercury(II) ions belong to the most toxic agents in the nature. Any assays of the photosynthetic capacity are sensitive to detect the harmful effects of the mercury(II) ion on intact bacterial cells. The detrimental effect of the light harvesting antenna can be visualized by decrease of the absorption bands in the near IR region attributed to peripheral (800-880 nm for Rps. rubrum and 800- $860 \mathrm{~nm}$ for Rvx. gelatinosus) and core (890 nm for Rps. rubrum and $875 \mathrm{~nm}$ for Rvx. gelatinosus) complexes (Fig. 1). After addition of mercury(II) ions to the bacterial culture in exponential growth phase, the duplication of the cells is terminated. Instead of increase, loss of the antenna complex is experienced. The $\mathrm{Hg}^{2+}$ ions have differential effects on bacterial strains and antenna complexes. In excess to absorption measurements, the detection of the $\mathrm{BChl}$ fluorescence induction is also a peculiarly adequate and sensitive assay to monitor any changes of the primary photosynthetic capacity upon heavy metal ion pollution (Fig. 2). The kinetics of fluorescence of the bacteria $(\mathrm{kfl}>850 \mathrm{~nm})$ upon rectangular shape of excitation by laser diode $(\mathrm{kex}=808 \mathrm{~nm})$ describe a monotonously increasing function from an initial level $\mathrm{F} 0$ to a maximum level $\mathrm{F}$ max. The variable fluorescence 
$\left(F_{v}=F_{\max } F_{0}\right)$ relative to maximum fluorescence $\left(F_{v} / F_{\max }\right)$ is a good indicator of the performance of the reaction center $(\mathrm{RC})$ related primary photochemistry: it will be high $\left(\mathrm{F}_{\mathrm{v}} / \mathrm{F}_{\max }>0.8\right)$ if the $\mathrm{RC}$ is well connected to the antenna and the captured energy is utilized in form of charge separation in the RC [40]. Any disturbances in the structure and function of the antenna-RC system will decrease the variable fluorescence. Fig. 2 demonstrates the dramatic collapse of the native arrangement after $5 \mathrm{~h}$ of mercury(II) treatment. Fig. 3 combines the effects of mercury concentrations and time of treatment for absorption (Fig. 3a) and fluorescence induction (Fig. 3b) measurements in strain Rhodospirillum rubrum. The marked difference between the band area of the untreated (control) and $\mathrm{Hg}^{2+}$-treated cells under illumination (10\% after $5 \mathrm{~h}$ incubation, Fig. 3a) is due to the fact that the bacteria without mercury were growing while the cells with mercury were not. The Fv/Fmax ratio performs large drop (from 0.6 to 0.1 ) within $5 \mathrm{~h}$ of treatment with $100 \mu \mathrm{M} \mathrm{Hg}^{2+}$ (Fig. 3b). The photosynthetic apparatus of strains of purple bacteria show different sensitivity against $\mathrm{Hg}(\mathrm{II})$ pollution. The $860 \mathrm{~nm}$ absorption band of the antenna of the strain Rvx. gelatinosus is more resistance to $\mathrm{Hg}^{2+}$ ions than that of the $860 \mathrm{~nm}$ band of Rps. rubrum (Fig. 1a and b). Considering the RC mediated primary photochemistry, the cells of Rvx. gelatinosus perform higher resistance against damaging effect of mercury(II) ions than those of Rps. rubrum
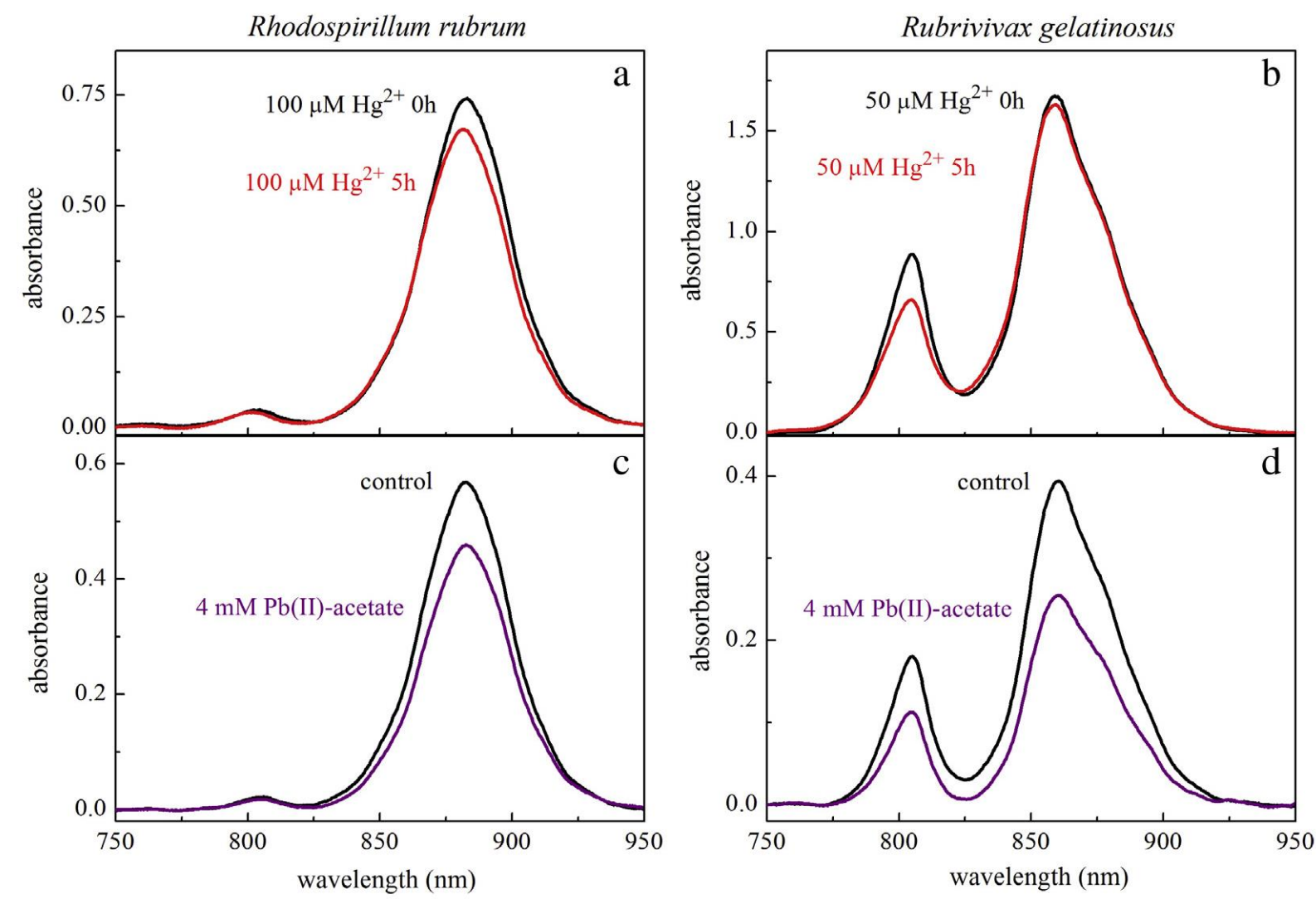

Fig. 1. Changes of the near IR steady state absorption spectra of intact cells of photosynthetic bacteria Rhodospirillum rubrum (left) and Rubrivivax gelatinosus (right) grown in the light upon addition of $\mathrm{HgCl}_{2}$ (panels a and b) and $\mathrm{Pb}$ (II) acetate (panels $\mathrm{c}$ and d) to the culture. Note that the mercury(II) ions cause temporal changes (compare the spectra taken after $0 \mathrm{~h}$ and $5 \mathrm{~h}$ treatments), the lead(II) ions set up prompt effects and the chromium(VI) ions have no effects (not shown). 

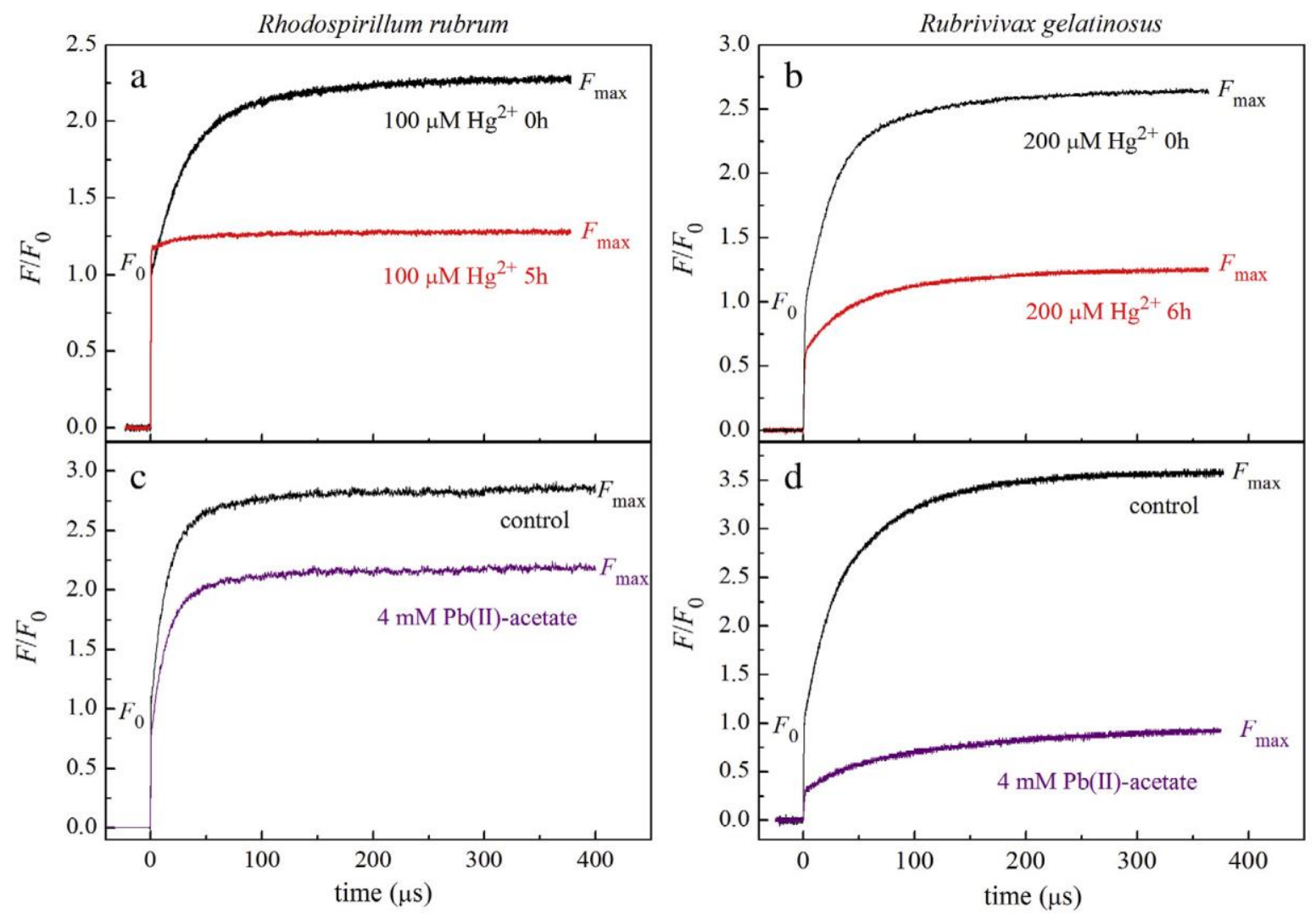

Fig. 2. Changes of the bacteriochlorophyll fluorescence induction kinetics of whole cells of Rhodospirillum rubrum (left) and Rubrivivax gelatinosus (right) kept in the light after selected time of incubation $(0$ and $5 \mathrm{~h}$ ) with $100 \mu \mathrm{M}$ mercury(II) ions (panels a and b) and addition of $4 \mathrm{mM}$ lead(II) ions (panels $\mathrm{c}$ and d). The kinetic traces are normalized to the initial Fo fluorescence levels of the untreated cells 


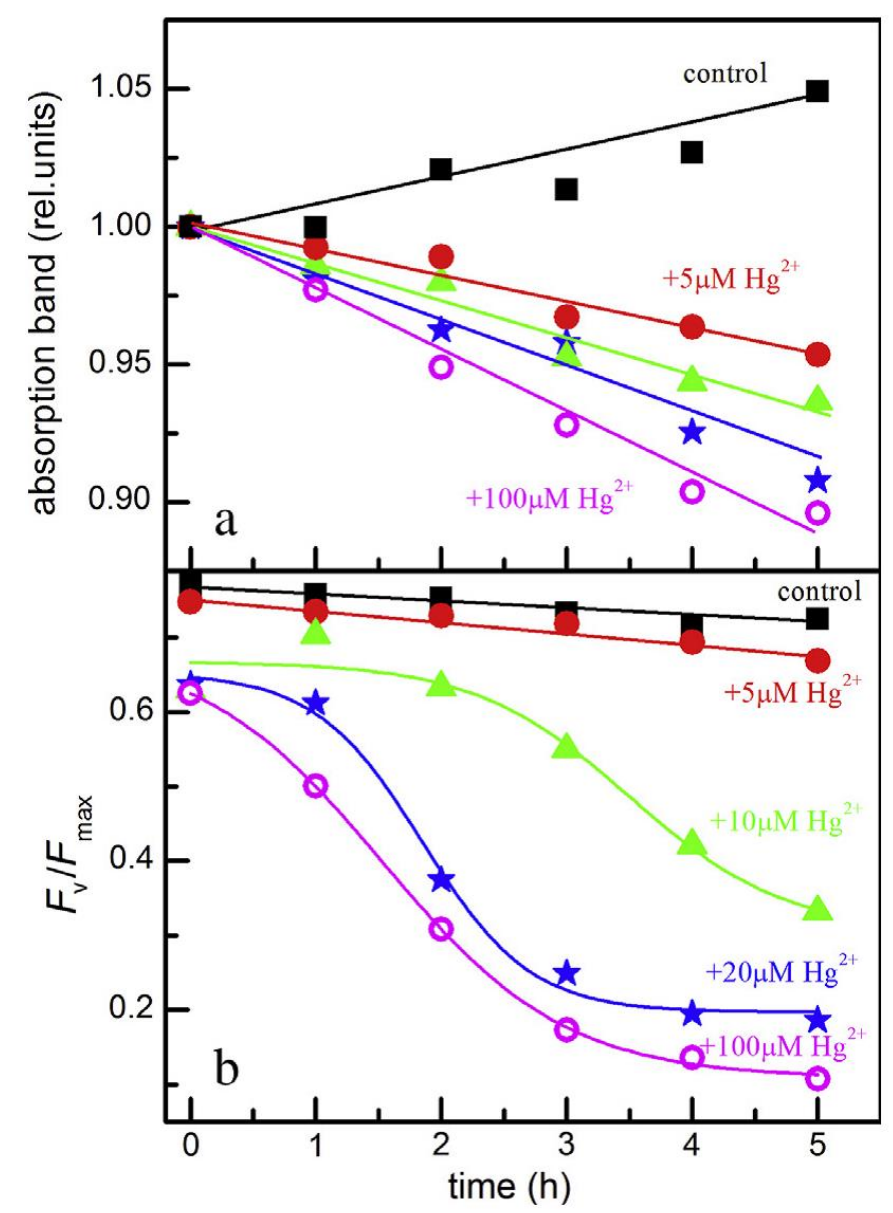

Fig. 3. Temporal changes of the area of steady state absorption bands (a) and the variable fluorescence (b) of intact cells of Rhodospirillum rubrum grown in the light and in the presence of variable amount of $\mathrm{HgCl}_{2}$. The absorption spectra (Fig. 1) were decomposed into Gauss components and the area of band centered at $860 \mathrm{~nm}$ were plotted. The series of applied $\mathrm{Hg}^{2+}$ concentrations amounted $0 \mu \mathrm{M} \mathrm{Hg} \mathrm{Hg}^{2+}(\mathrm{j}),+5 \mu \mathrm{M} \mathrm{Hg}^{2+}(\mathrm{d}),+10 \mu \mathrm{M} \mathrm{Hg}^{2+}(\mathrm{N}),+20 \mu \mathrm{M} \mathrm{Hg} \mathrm{Hg}^{2+}(\mathrm{H})$ and $+100 \mu \mathrm{M} \mathrm{Hg}{ }^{2+}$

(s).

(Fig. 2a and b). While $20 \mu \mathrm{M} \mathrm{Hg}^{2+}$ bleaches the cells of Rps. rubrum within 2-3 $\mathrm{h}$ and the rate of growth of Rba. sphaeroides culture is halved at $2 \mu \mathrm{M} \mathrm{Hg}^{2+}$ concentration [41], orders of magnitude larger concentration $(200 \mu \mathrm{M})$ does not cause significant damage in cells of $R v x$. gelatinosus (Fig. 2b). The strains Rba. sphaeroides and Rps. rubrum demonstrate orders of magnitude higher sensitivity to mercury(II) ions than to other heavy metal ions [7]. Some fungal strains were found to be more tolerant to higher concentrations of metal ions than photosynthetic bacteria in our study and they also demonstrated larger activity of metal ion removal from the polluted environment (bioremediation) $[42,43]$. Although the concentrations used in these works were toxic to all of the microbial strains, yet the higher removal of the metal ions indicated that the fungi had profound ability of metal uptake during its growth. Transmission electron micrographs of thin cell sections of Rps. rubrum (Fig. 4) indicate that the observed functional damage of the photosynthetic apparatus due to mercury(II) ions can be correlated to morphological changes in the intracellular membranes of the cell. At $0 \mathrm{~h}$ before the mercury treatment, the cells are filled up with vesicular intracytoplasmic membranes (ICM) formed from invagination of the cytoplasmic membrane (CM). The membrane vesicles are seen mainly in close opposition to the outer membrane (Fig. 4a). After $24 \mathrm{~h}$ of treatment with $10 \mu \mathrm{M} \mathrm{Hg}^{2+}$ ion, substantial morphological changes can be experienced (Fig. 4b): the majority of the membrane vesicles disappear in accordance with the loss of photosynthetic activity of the cells. The $\mathrm{Hg}^{2+}$ ions of the contaminated environment are adsorbed on the surface of the cell and transported into the cell by "open gate" mechanism i.e. by one of the physiological transport systems (e.g. magnesium uptake pathway). As the mercury ions have no physiological function, the bacterium tries to decrease the internal mercury concentration by either the transient loss of the uptake system, or by the temporary increase of the efficiency of the efflux system or by the enzymatic detoxification encoded by the mer operon, which can be located on plasmids, chromosomes or transposons [44]. Due to enzymatic detoxification, part of the $\mathrm{Hg}^{2+}$ ions are reduced by the mercuric reductase MerA, a glutathione reductase related enzyme, converting the cation to metallic mercury [45]. $\mathrm{Hg}^{2+}$ is volatile and leaves the cell by passive diffusion [46]. The mercury(II) ions being accumulating in the cell have strong affinity toward the thiol groups and express strong toxicity resulting the damage of the biosynthetic pathway of $\mathrm{BChl}$ and heme [47], and the photosynthetic apparatus (Figs. 1-3). The mercury(II) ion exerts the harmful effect on the photosynthetic machinery in sequential manner depending on the bacterial strain. In Rba. sphaeroides, the RC is the primary target and less sensitive molecular complexes are the cytochrome bc1 and the light harvesting system [19]. Although the RC protein can preserve its ability for light-induced charge separation up to high mercury concentration $\left(\left[\mathrm{Hg}^{2+}\right] /[\mathrm{RC}]<500\right)$, the internal electron transfer is impeded at much lower mercury level. The most sensitive reaction is the Qв related electron transfer which is blocked at one order of magnitude smaller $\left(\left[\mathrm{Hg}^{2+}\right] /[\mathrm{RC}]<50\right)$ mercury concentration. 

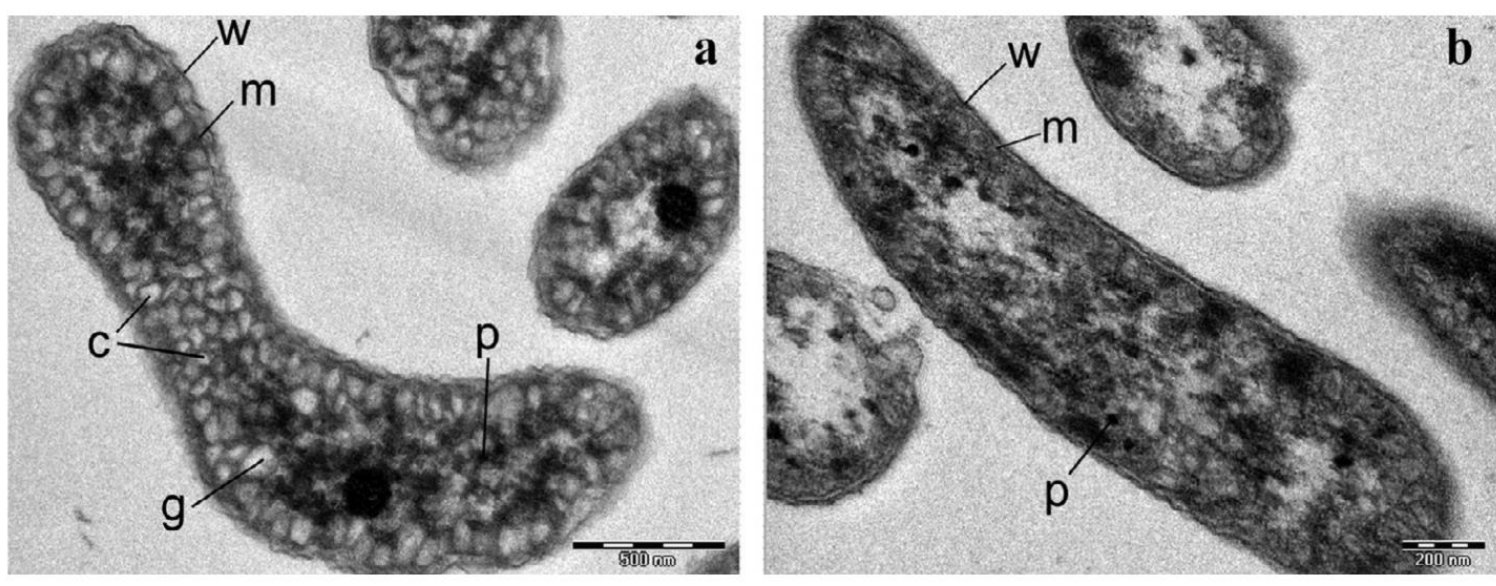

Fig. 4. Electron micrographs of longitudinal and transversal sections of Rhodospirillum rubrum growing anaerobically in the light (a) and in the presence of 10 $\mu \mathrm{M} \mathrm{Hg}^{2+}$ overnight (b). The characteristic regions of the fine cellular structure (cell wall (w), cell membrane (m), chromatophores (c), glycogen granules (g) and polyphosphate (p)) can be identified [68]. Magnification 34,000 (a), 46,000 (b).

system, or by the temporary increase of the efficiency of the efflux system or by the enzymatic detoxification encoded by the mer operon, which can be located on plasmids, chromosomes or transposons [44]. Due to enzymatic detoxification, part of the $\mathrm{Hg}^{2+}$ ions are reduced by the mercuric reductase MerA, a glutathione reductase related enzyme, converting the cation to metallic mercury [45]. $\mathrm{Hg}^{2+}$ is volatile and leaves the cell by passive diffusion [46]. The mercury(II) ions being accumulating in the cell have strong affinity toward the thiol groups and express strong toxicity resulting the damage of the biosynthetic pathway of BChl and heme [47], and the photosynthetic apparatus (Figs. 1-3). The mercury(II) ion exerts the harmful effect on the photosynthetic machinery in sequential manner depending on the bacterial strain. In Rba. sphaeroides, the RC is the primary target and less sensitive molecular complexes are the cytochrome bc1 and the light harvesting system [19]. Although the RC protein can preserve its ability for light-induced charge separation up to high mercury concentration $\left(\left[\mathrm{Hg}^{2+}\right] /\left[\mathrm{RC}^{2}<500\right)\right.$, the internal electron transfer is impeded at much lower mercury level. The most sensitive reaction is the Qв related electron transfer which is blocked at one order of magnitude smaller $\left(\left[\mathrm{Hg}^{2+}\right] /[\mathrm{RC}]<50\right)$ mercury concentration.

\subsubsection{Chromium(VI) ion}

Chromium is both an essential trace element as $\mathrm{Cr}(\mathrm{IIII})$ ion and an environmental toxicant as $\mathrm{Cr}(\mathrm{VI})$ ion. They display quite different chemical properties, solubility and toxicity. $\mathrm{Cr}(\mathrm{III})$ is immobile, exists mostly bound to organic matter in soil and aquatic environments and is harmless. In contrast, $\mathrm{Cr}(\mathrm{VI})$ is a strong oxidizing agent and its compounds are very soluble in water and mobile in the environment [48]. $\mathrm{Cr}(\mathrm{VI}) \mathrm{species}$ are acutely toxic, mutagenic, teratogenic and carcinogenic to all forms of life [49-51]. The high toxicity of $\mathrm{Cr}(\mathrm{VI})$ ion can be demonstrated by modification of flash-induced electrochromic bandshift in intact cells of Rvx. gelatinosus in comparison with the similar effects due to $\mathrm{Hg}$ (II) and $\mathrm{Pb}$ (II) heavy metal ions (Fig. 5). The assay is based on absorption changes (electrochromisms) of reporter (carotenoid) molecules induced by internal electric field in the photosynthetic membrane. The prompt accumulation of charges due to RC and cyt bc1 complexes on both sides of the membrane establishes large initial electrochromic change that is progressively decreased upon removal (or compensation) of charges by subsequent electron and proton transfer reactions in the dark. The complexity of these reactions (i.e. the discharge of the membrane capacitor) is indicated by the biphasic character of both the rise and the decay of the kinetics of the electrochromic change [19]. Addition of $\mathrm{Cr}$ (III) ion of high (up to $20 \mathrm{mM}$ ) concentration to the culture, the kinetics will be not modified to that of the intact cells (control) supporting the harmless nature of the trivalent form of chromium (not shown). 


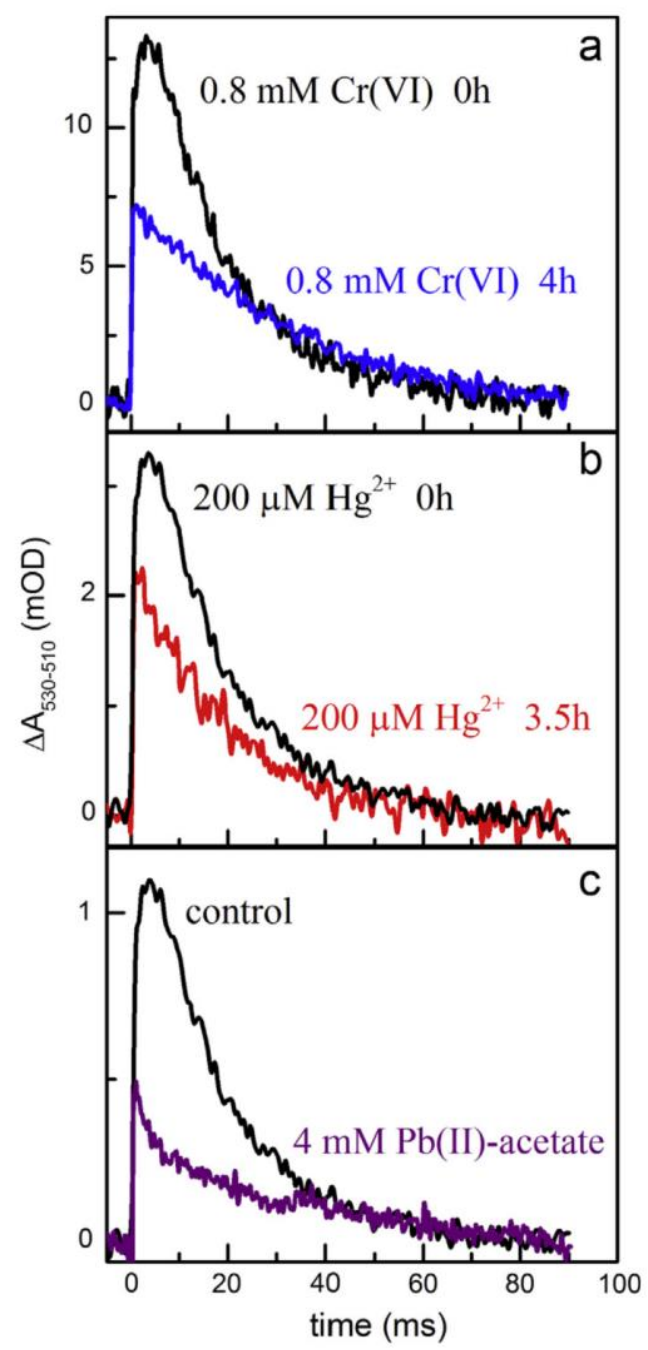

Fig. 5. Kinetics of flash-induced electrochromic response of the carotenoids measured by absorption change at $530 \mathrm{~nm}$ (vs. $510 \mathrm{~nm}$ ) of whole cells of Rubrivivax gelatinosus grown in the light upon treatment with $0.8 \mathrm{mM} \mathrm{Cr}(\mathrm{VI})$ for $4 \mathrm{~h}$ (a), $0.2 \mathrm{mM} \mathrm{Hg}$ (II) for $3.5 \mathrm{~h}$ (b) and $4 \mathrm{mM} \mathrm{Pb}$ (II) (prompt effect, c).

The treatment with $0.8 \mathrm{mM} \mathrm{Cr}(\mathrm{VI})$, however, reduces the amplitude of the fast rise to half, eliminates the slow component of the rising phase and removes the fast component but preserves the slow phase of the decay. The observation suggests the appearance of sever block of electron and proton transfer between RC and cyt bc1 complexes due to the effect of $\mathrm{Cr}(\mathrm{VI})$. Qualitatively similar changes of the membrane energetization/discharge will be performed by mercury(II) and lead(II) heavy metal ions as late and prompt effects, respectively. The different biological effects of the trivalent and hexavalent forms of the metal are caused by the cellular uptake process: the oxyanion (CrO4 2$)$ crosses the cellular membranes via surface anion transport systems ( $\mathrm{SO}_{4} 2$ and $\mathrm{HPO}_{4} 2$ channels), reacts with nucleic acids and other cellular components and cause oxidation and cellular damage [52]. In soil and water the less toxic $\mathrm{Cr}$ (III) ion can be oxidized to carcinogenic and mutagenic chromium, $\mathrm{Cr}(\mathrm{VI})$. In the presence of organic matter (living organisms) $\mathrm{Cr}$ (VI) can be reduced to $\mathrm{Cr}$ (III); this transformation is faster in acidic aquatic environments [53].

\subsubsection{Lead(II) ion}

Lead is also a hazardous environmental pollutant that is toxic to bacterial cells even at low concentrations [23]. It is known to cause damage to DNA, protein and lipid and to replace essential metal ions such as $\mathrm{Zn}, \mathrm{Ca}$ and $\mathrm{Fe}$ from enzymes. The aggressive nature of $\mathrm{Pb}(\mathrm{II})$ is expressed by severe prompt effects on near IR steady state absorption spectra (Fig. 1c and d) and BChl fluorescence induction (Fig. 2c and d) of whole cells of Rps. rubrum and Rvx. gelatinosus. As the decrease of the IR absorption characteristic to the light harvesting system of the bacteria is not specific but general, it can be stated that $\mathrm{Pb}$ (II) ions in several $\mathrm{mM}$ concentrations cause prompt and significant destruction of all antenna complexes. The BChl fluorescence induction kinetics of the bacterial cultures demonstrate similarly prompt changes: the lead treatment decreases both the initial $\left(F_{0}\right)$ and the maximum ( $F_{\max }$ ) fluorescence levels without modifying the variable fluorescence (the $F_{v} / F_{\max }$ value) significantly. This is in contrast to late effect of mercury(II) that decreased the variable fluorescence without severe modification of the initial fluorescence level (Fig. 2a). While heavy metal ions had to be added to the bacterial culture generally in (sub) millimolar concentrations to manifest their late effects of substantial damage, lead acetate in similar concentrations demonstrated similar but prompt effects. That makes clear how harmful is the lead pollutant. On one hand, the lead(II) ion performs high penetration through the cell wall and attacks and bleaches the $\mathrm{BChl}$ molecules directly. Additionally, it decreases the magnitude of light-induced electrochromism that is characteristic of the energetization of the photosynthetic membrane (Fig. 5c). On the other hand, $\mathrm{Pb}$ (II) prohibits the fast component of discharge of the energetized membrane. Probably due to the prompt effect studied here, no time remains for the lead ions to randomize the molecular arrangement and to 
remove the connections among the molecular complexes (antenna, RC and cyt bc1) in the membrane. In agreement with the conclusion of substantial prompt loss of BChl upon lead treatment, we observe decrease of the photochemical rate constant (increase of the rise time of the induction) which is the direct consequence of the decreases of the absorption cross sections of the antenna. Lead(II) is dangerous not only because of its marked prompt effects shown above but also of its slow accumulation in living organisms. The accumulation leads to biomagnifications at different tropic levels in food chains and is therefore referred to as a cumulative poison [54]. Based on our results, we can argue that the bacterial strains are sensitive tools to biomonitor lead contaminated environmental sites and can contribute to their bioremediation.

\subsection{Transitions between aerobic and anaerobic conditions}

When the atmosphere of the Rvx. gelatinosus cells grown under anaerobic conditions in the light is changed from $\mathrm{N}_{2}$ to air (20\% $\mathrm{O}_{2}$ ), a gratuitous destruction of the ICM assembly together with the decrease of the rate of synthesis and assembly of light-harvesting and reaction center complexes can be observed (Fig. 6). Not only the variable fluorescence but also the relative portion of the peripheral antenna (LH2) to the core antenna (LH1) decrease during the bleaching process that is similar but much longer than that of Rba. sphaeroides under identical conditions [31]. After nearly complete loss of pigmentation and photosynthetic activity, the culture is set to anaerobic condition ( $\mathrm{N}_{2}$ atmosphere) and the purple bacteria starts to form via invagination of CM a system of ICM that houses the photosynthetic apparatus ("'greening'). After similarly long greening process as was the bleaching process (several $10 \mathrm{~h}$ ), the photosynthetic apparatus and function reach the stationary values characteristic of mature and well developed cells. The functional changes upon aerobic to anaerobic transition are reflected by morphological changes of the cells. In some bacteria grown anaerobically (e.g. Rba. sphaeroides and Rps. rubrum) the membrane vesicles are well separated and can be recognized easily in the electron micrographs (Fig. 7a), but in some other bacterial strains (e.g. $R v x$. gelatinosus) the apparatus is not so well localized and is more distributed (Fig. 7c). The increase of the oxygen partial pressure results in morphological consequences that are straightforward on the electron micrograph of Rba. sphaeroides (Fig. 7b) and less pronounced on that of Rvx. gelatinosus (Fig. 7d). These developmental changes are under the control of a global oxygen sensing and signal transduction system $[55,56]$. The molecular mechanisms of photosystem regulation in purple bacteria according to environmental conditions have been now well characterized [57,58]. Three major regulatory systems have been discovered and characterized: (i) the RegB/RegA (PrrB/PrrA) two-component regulatory system [59], (ii) the anaerobic activator FnrL [60,61] and (iii) the aerobic repressor PpsR [62,63]. In contrast to RegB/RegA and FnrL, which are global regulatory proteins, the PpsR proteins are particularly involved in PS regulation. The PpsR proteins have been mainly characterized in the two closely related species Rba. sphaeroides and Rba. capsulatus [64-66] and in Rvx. gelatinosus where PpsR can act both as an activator and as a repressor, depending on the photosynthesis genes [67].

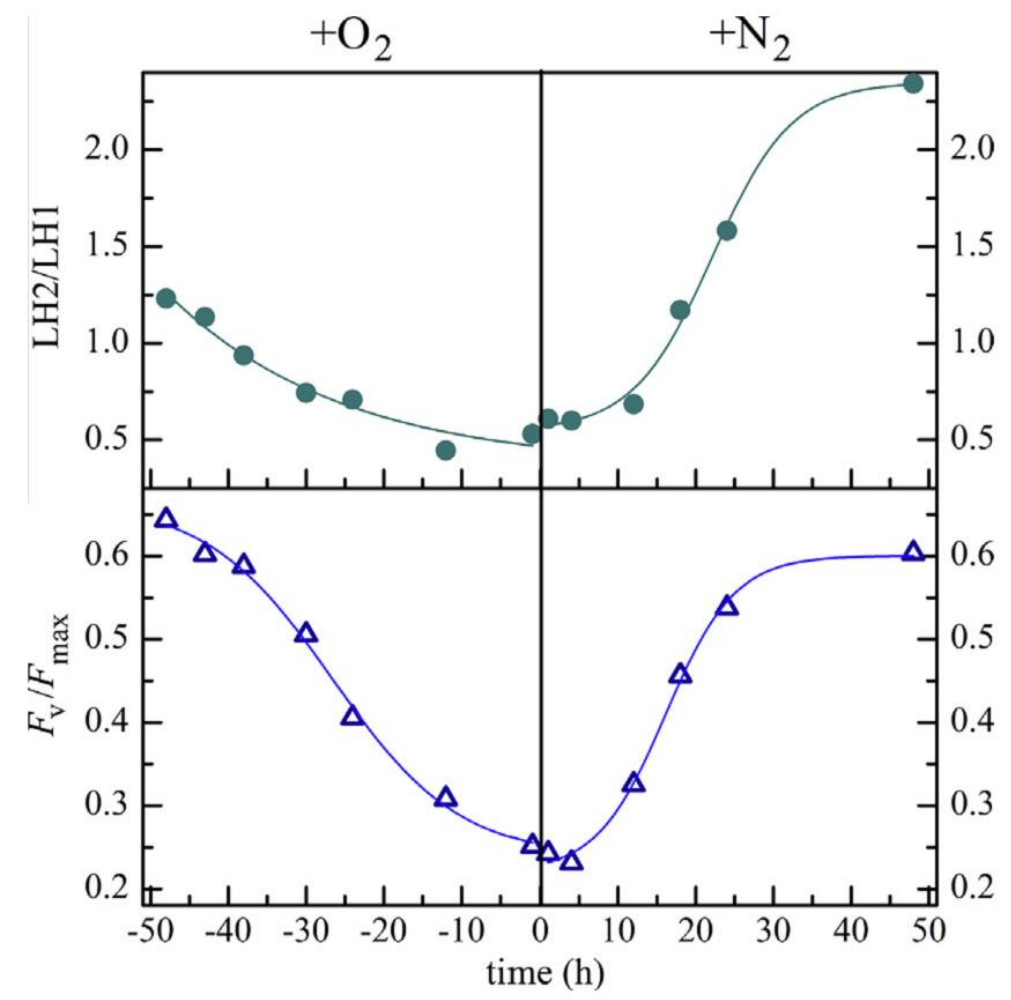

Fig. 6. Time-dependent structural and functional characteristics of photosynthetic membrane of Rubrivivax gelatinosus grown aerobically $\left(+\mathrm{O}_{2}\right)$ and then transferred to anaerobic $\left(+\mathrm{N}_{2}\right)$ conditions. The development or re-arrangement of the photosynthetic apparatus in the membrane is characterized by the relative variable fluorescence $\left(\mathrm{F}_{\mathrm{v}} / \mathrm{F}_{\max }\right)$ and the ratio of the two light harvesting systems (OD850/ OD875 is identified as LH2/LH1). 


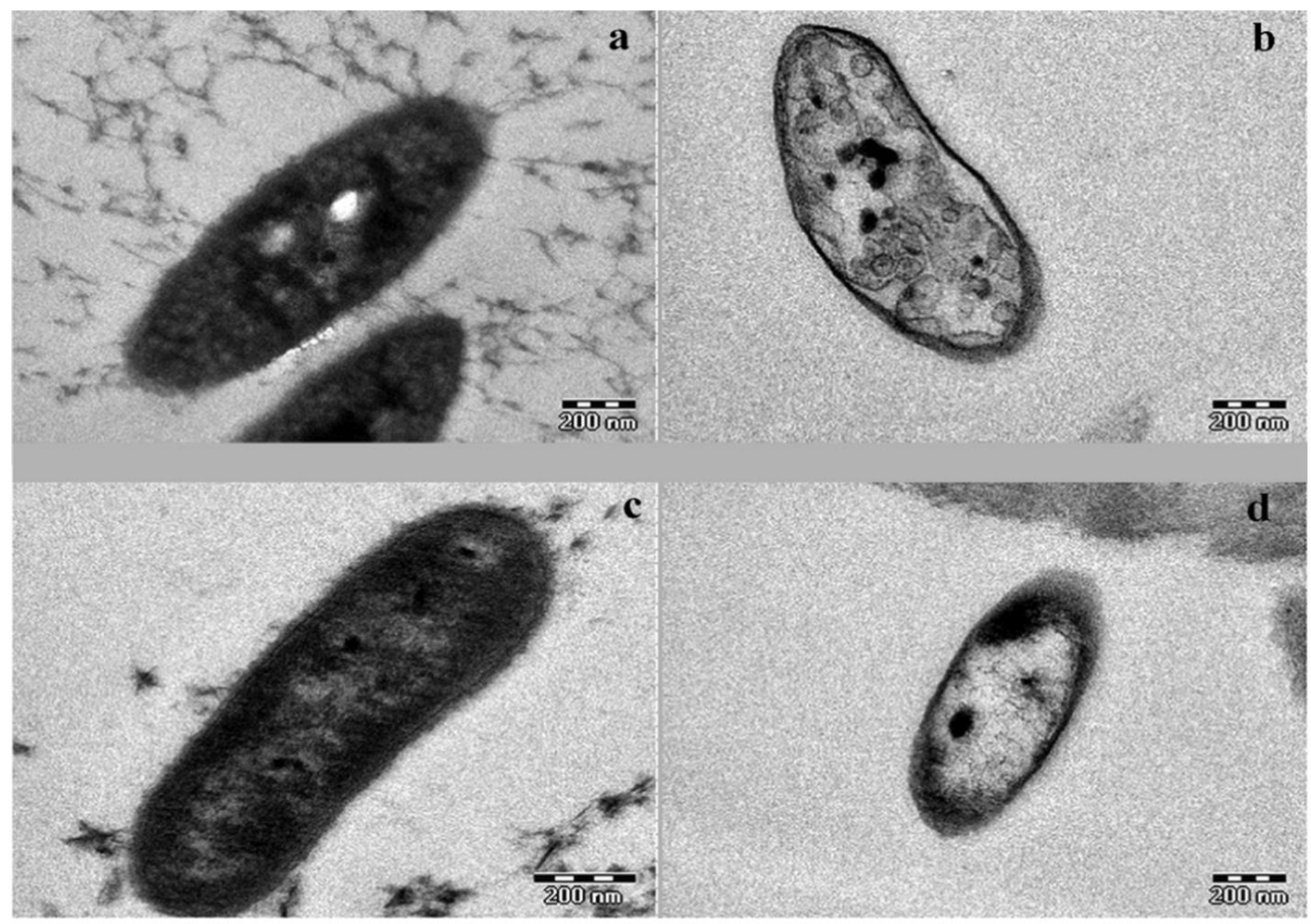

Fig. 7. Electron micrographs of longitudinal sections of Rhodobacter sphaeroides 2.4 .1 grown anaerobically (a) and aerobically (b) and the same for Rubrivivax gelatinosus (c and d). Magnification 46,000 (a, b, d) and 64,000 (c).

\section{Conclusions}

A wealth of experimental results were presented how photosynthetic purple bacteria respond to environmental stresses including heavy metal pollution and oxygen deficiency in aqueous habitats. After bioadsorption on the cell surface and transfer through the cell wall, the pollutants are either sequestrated (immobilized) by the living organisms or interfere with metabolic processes and start to demolish the structure and function of the bacteria. The strain of bacteria and type of heavy metal ions will primarily determine which scenario and what prompt and late damages will occur. Measurements of steady state and kinetic absorption and BChl fluorescence induction together with electron micrographs have been proved adequate and sensitive methods to detect the consequences of the environmental stresses. The wide range of tested bacteria and assays enable us to select the optimal combination to monitor the pollution in relatively early phase in environment of aqueous habitats.

\section{Acknowledgements}

Thanks to TÁMOP (4.2.2.A-11/1KONV-2012-0060, 4.2.2.B and 4.2.2.D-15/1/KONV-2015-0024), COST (CM1306), OTKA and Swiss Contribution (SH/7/2/20) programs for financial support. We are indebted to Ms. Erika Németh for the thin cell sections.

\section{References}

[1] P.G. Falkowski, J.A. Raven, Aquatic Photosynthesis, second ed., Princeton University Press, 2007.

[2] M. Koblizek, J.D. Shih, S.I. Breitbart, C. Ratcliffe, Z.S. Kolber, C.N. Hunter, R.A. Niederman, Sequential assembly of photosynthetic units in Rhodobacter sphaeroides as revealed by fast repetition rate analysis of variable bacteriochlorophyll a fluorescence, Biochim. Biophys. Acta 1706 (2005) $220-231$.

[3] E. Hojerová, M. Mašín, C. Brunet, I. Ferrera, J.M. Gasol, M. Koblíz `ek, Distribution and growth of aerobic anoxygenic phototrophs in the Mediterranean Sea, Environ. Microbiol. 13 (10) (2011) 2717-2725.

[4] H. Medová, E.N. Boldareva, P. Hrouzek, S.V. Borzenko, Z.B. Namsaraev, V.M. Gorlenko, B.B. Namsaraev, M. Koblíz `ek, High abundances of aerobic anoxygenic phototrophs in saline steppe lakes, FEMS Microbiol. Ecol. 76 (2) (2011) 393-400

[5] I. Ferrera, J.M. Gasol, M. Sebastián, E. Hojerová, M. Koblizek, Comparison of growth rates of aerobic anoxygenic phototrophic bacteria and other bacterioplankton groups in coastal Mediterranean waters, Appl. Environ. Microbiol. 77 (21) (2011) 7451-7458.

[6] G.M. Gadd, Bioremedial potential of microbial mechanisms of metal mobilization and immobilization, Curr. Opin. Biotechnol. 11 (2000) $271-279$.

[7] L. Giotta, A. Agostiano, F. Italiano, F. Milano, M. Trotta, Heavy metal ion influence on the photosynthetic growth of Rhodobacter sphaeroides, Chemosphere 62 (2006) 1490-1499. 
[8] F. Borsetti, P.L. Martelli, R. Casadio, D. Zannoni, Metals and metalloids in photosynthetic bacteria: interactions, resistance and putative homeostasis revealed by genome analysis, in: The Purple Phototrophic Bacteria, Springer, Dordrecht, The Netherlands, 2009, pp. 655-689.

[9] D.H. Nies, Resistance to cadmium, cobalt, zinc, and nickel in microbes, Plasmid 27 (1992) 17-28.

[10] J.E. Sloof, A. Viragh, B. Vanderveer, Kinetics of cadmium uptake by green-algae, Water Air Soil Pollut. 83 (1-2) (1995) 105-122.

[11] I. Bakkaloglu, T.J. Butter, L.M. Evison, F.S. Holland, I.C. Hancock, Screening of various types biomass for removal and recovery of heavy metals (Zn, Cu, Ni) by biosorption, sedimentation and desorption, Water Sci. Technol. 38 (2-3) (1998) 114-122.

[12] S.S. Ahluwalia, G. Dinesh, Microbial and plant derived biomass for removal of heavy metals from wastewater, Bioresour. Technol. 98 (12) (2007) 22432257.

[13] G.M. Gadd, Metals and microorganisms: a problem of definition, FEMS Microbiol. Lett. 79 (1992) 197-203.

[14] A. Malik, Metal bioremediation through growing cells, Environ. Int. 30 (2004) 261-278.

[15] R. Munoz, B. Guieyss, Algal-bacterial processes for the treatment of hazardous contaminants: a review, Water Res. 40 (15) (2006) $2799-2815$.

[16] M.D. Moore, S. Kaplan, Members of the family Rhodospirillaceae reduce heavy metal oxyanions to maintain redox poise during photosynthetic growth, ASM News 60 (1994) 17-23.

[17] R.M. Gabr, S.H.A. Hassan, A.A.M. Shoreit, Biosorption of lead and nickel by living and non-living cells of Pseudomonas aeruginosa ASU 6a, Int. Biodeterior. Biodegradation 62 (2008) 195-203.

[18] P.R. Puranik, K.M. Paknikar, Biosorption of lead, cadmium, and zinc by Citrobacter strain MCM B-181: characterization studies, Biotechnol. Prog. 15 (1999) 228-237.

[19] E. Asztalos, G. Sipka, M. Kis, M. Trotta, P. Maróti, The reaction center is the sensitive target of the mercury(II) ion in intact cells of photosynthetic bacteria, Photosynth. Res. 112 (2012) 129-140.

[20] M.N. Hughes, R.K. Poole, Metals and Microorganism, Chapman and Hall, London, 1989, pp. 280-285.

[21] R.K. Poole, G.M. Gadd, Metals: Microbe Interactions, IRL Press, Oxford, 1989, pp. 1-37.

[22] S. Silver, Bacterial resistances to toxic metal ions-a review, Gene 179 (1996) 9- 19.

[23] D.H. Nies, Microbial heavy-metal resistance, Appl. Microbiol. Biotechnol. 51 (1994) 730-750.

[24] M.R. Bruins, S. Kapil, F.W. Oehme, Microbial resistance to metals in the environment, Ecotoxicol. Environ. Saf. 45 (2000) 198-207. Fig. 7. Electron micrographs of longitudinal sections of Rhodobacter sphaeroides 2.4 .1 grown anaerobically (a) and aerobically (b) and the same for Rubrivivax gelatinosus (c and d). Magnification 46,000 (a, b, d) and 64,000 (c). 116 M. Kis et al. / Journal of Photochemistry and Photobiology B: Biology 151 (2015) 110-117

[25] M. Valls, V. de Lorenzo, Exploiting the genetic and biochemical capacities of bacteria for the remediation of heavy metal pollution, FEMS Microbiol. Rev. 26 (2002) 327-338.

[26] M. Kim, J.L. Won, H.J. Kim, S.K. Lee, S.J. Lee, T. Kim, Chemostat-like microfluidic platform for highly sensitive detection of heavy metal ions using microbial biosensors, Biosens. Bioelectron. 65 (2015) 257-264.

[27] G. Tsekenis, M.K. Filippidou, M. Chatzipetrou, V. Tsouti, I. Zergioti, S. Chatzandroulis, Heavy metal ion detection using capacitive micromechanical biosensors for environmental monitoring, Sens. Actuators B: Chem. 208 (2015) 628-635.

[28] L. Cui, J. Wu, H. Ju, Electrochemical sensing of heavy metal ions with inorganic, organic and bio-materials, Biosens. Bioelectron. 63 (2015) 276-286.

[29] K. Woronowicz, J.W. Harrold, J.M. Kay, R.A. Niederman, Structural and functional proteomics of intracytoplasmic membrane assembly in Rhodobacter sphaeroides, J. Mol. Microbiol. Biotechnol. 23 (2013) 48-62.

[30] R. Niederman, Membrane development in purple photosynthetic bacteria in response to alterations in light intensity and oxygen tension, Photosynth. Res. 116 (2013) 333-348.

[31] M. Kis, E. Asztalos, G. Sipka, P. Maróti, Assembly of photosynthetic apparatus in Rhodobacter sphaeroides as revealed by functional assessments at different growth phases and in synchronized and greening cells, Photosynth. Res. 122 (2014) 261-273.

[32] F. Italiano, A. Buccolieri, L. Giotta, A. Agostiano, L. Valli, F. Milano, M. Trotta, Response of the carotenoidless mutant Rhodobacter sphaeroides growing cells to cobalt and nickel exposure, Int. Biodeterior. Biodegradation 63 (2009) 948- 957.

[33] F. Italiano, G.M. D’Amici, S. Rinalducci, F. De Leo, L. Zolla, R. Gallerani, M. Trotta, L.R. Ceci, The photosynthetic membrane proteome of Rhodobacter sphaeroides R-26.1 exposed to cobalt, Res. Microbiol. 162 (5) (2011) 520-527.

[34] X. Deng, P. Jia, Construction and characterization of a photosynthetic bacterium genetically engineered for $\mathrm{Hg}^{2+}$ uptake, Bioresour. Technol. 102 (2011) 3083-3088

[35] P. Kocsis, E. Asztalos, Z. Gingl, P. Maróti, Kinetic bacteriochlorophyll fluorometer, Photosynth. Res. 105 (2010) 73-82.

[36] W.R. Siström, The kinetics of the synthesis of photopigments in Rhodopseudomonas sphaeroides, J. Gen. Microbiol. 28 (1962) 607-616

[37] P. Maróti, C.A. Wraight, Flash-induced $\mathrm{H}_{+}$binding by bacterial photosynthetic reaction centers: comparison of spectrometric and conductometric methods, Biochim. Biophys. Acta 934 (1998) 314-328.

[38] M.D. Moore, S. Kaplan, Identification of intrinsic high level resistance to rareearth oxides and oxyanions in members of the class proteobacteria: characterization of tellurite, selenite, and rhodium sesquioxide reduction in Rhodobacter sphaeroides, J. Bacteriol. 174 (1992) $1505-1514$

[39] R.K. Watt, P.W. Ludden, $\mathrm{Ni}^{2+}$ transport and accumulation in Rhodospirillum rubrum, J. Bacteriol. 181 (1999) 4554-4560. 
[40] J. Lavergne, H.W. Trissl, Theory of fluorescence induction in photosystem II: derivation of analytical expressions in a model including exciton-radical-pair equilibrium and restricted energy transfer between photosynthetic units, Biophys. J. 68 (1995) 2474-2492.

[41] E. Asztalos, F. Italiano, F. Milano, P. Maróti, M. Trotta, Early detection of mercury contamination by fluorescence induction of photosynthetic bacteria, Photochem. Photobiol. Sci. 9 (2010) 1218-1223.

[42] A. Mishra, A. Malik, Novel fungal consortium for bioremediation of metals and dyes from mixed waste stream, Bioresour. Technol. 171 (2014) 217-226.

[43] A. Mishra, A. Malik, Metal and dye removal using fungal consortium from mixed waste stream: optimization and validation, Ecol. Eng. 69 (2014) 226231.

[44] D. Reniero, E. Galli, P. Barbieri, Cloning and comparison of mercury and organomercurial-resistance determinants from a Pseudomonas stutzeri plasmid, Gene 166 (1995) 77-82.

[45] N. Schiering, W. Kabsch, M.J. Moore, M.D. Distefano, C.T. Walsh, E.F. Pai, Structure of the detoxification catalyst mercuric ion reductase from Bacillus sp. strain RC607, Nature 352 (1991) 168-172.

[46] S. Silver, L.T. Phung, Bacterial heavy metal resistance. New surprises, Ann. Rev. Microbiol. 50 (1996) 753-789.

[47] F. Pisani, F. Italiano, F. de Leo, R. Gallerani, S. Rinalducci, L. Zolla, A. Agostiano, L.R. Ceci, M. Trotta, Soluble proteome investigation of cobalt effect on the carotenoidless mutant of Rhodobacter sphaeroides, J. Appl. Microbiol. 106 (2009) 338-349.

[48] M. Cieslak-Golonka, Toxic and mutagenic effects of chromium(VI). A review, Polyhedron 15 (2005) 3667-3689.

[49] D. Bagchi, S.J. Stohs, D.W. Downs, M. Bagchi, H.G. Preuss, Cytotoxicity and oxidative mechanisms of different forms of chromium, Toxicology 180 (2002) 5-22.

[50] R. von Burg, D. Liu, Chromium and hexavalent chromium, J. Appl. Toxicol. 13 (1993) 225-230.

[51] D.G. Barceloux, Chromium, J. Toxicol. Clin. Toxicol. 37 (1999) 173-194.

[52] J. McLean, T.J. Beveridge, Chromate reduction by a pseudomonad isolated from a site contaminated with chromated copper arsenate, Appl. Environ. Microbiol. 67 (2001) 1076-1084.

[53] S.P. McGrath, S. Smith, Chromium and nickel, in: B.J. Alloway (Ed.), Heavy Metals in Soils, Wiley, New York, 1990, pp. 125-150.

[54] P.E. Lombardi, S.I. Peri, N.R. Verrengia, ALA-D and ALA-D reactivated as biomarkers of lead contamination in the fish Prochilodus lineatus, Ecotoxicol. Environ. Saf. 73 (2010) 1704-1711.

[55] J.M. Eraso, S. Kaplan, PrrA, a putative response regulator involved in oxygen regulation of photosynthesis gene expression in Rhodobacter sphaeroides, J. Bacteriol. 176 (1994) 32-43.

[56] L.R. Swem, S. Elsen, T.H. Bird, D.L. Swem, H.-G. Koch, M. Myllykallio, F. Daldal, C.E. Bauer, The RegB/RegA two-component regulatory system controls synthesis of photosynthesis and respiratory electron transfer components in Rhodobacter capsulatus, J. Mol. Biol. 309 (2001) $121-138$.

[57] J.I. Oh, S. Kaplan, Generalized approach to the regulation and integration of gene expression, Mol. Microbiol. 39 (2001) $1116-1123$.

[58] C.E. Bauer, S. Elsen, L.R. Swem, D.L. Swem, S. Masuda, Redox and light regulation of gene expression in photosynthetic prokaryotes, Phil. Trans. Roy Soc. Lond. B. Biol. Sci. 358 (2003) 147-154.

[59] S. Elsen, L.R. Swem, D.L. Swem, C.E. Bauer, RegB/RegA, a highly conserved redox-responding global two-component regulatory system, Microbiol. Mol. Biol. Rev. 68 (2004) 263-279.

[60] J.H. Zeilstra-Ryalls, S. Kaplan, Role of the fnrL gene in photosystem gene expression and photosynthetic growth of Rhodobacter sphaeroides 2.4.1, J. Bacteriol. 180 (6) (1998) 1496-1503.

[61] J.H. Zeilstra-Ryalls, S. Kaplan, Oxygen intervention in the regulation of gene expression: the photosynthetic bacterial paradigm, Cell. Mol. Life Sci. 61 (2004) 417-436.

[62] R.J. Penfold, J.M. Pemberton, Sequencing chromosomal inactivation and functional expression in Escherichia coli of ppsR, a gene which represses carotenoid and bacteriochlorophyll synthesis in Rhodobacter sphaeroides, J. Bacteriol. 176 (1994) 2869-2876.

[63] S.N. Ponnampalam, S. Bauer, DNA binding characteristics of CrtJ-A redoxresponding repressor of bacteriochlorophyll, carotenoid, and light harvestingII gene expression in Rhodobacter capsulatus, J. Biol. Chem. 272 (1997) 18391- 18396.

[64] M. Gomelsky, S. Kaplan, Molecular genetic analysis suggesting interactions between AppA and PpsR in regulation of photosynthesis gene expression in Rhodobacter sphaeroides 2.4.1, J. Bacteriol. 179 (1997) 128-134.

[65] S. Masuda, C.E. Bauer, AppA is a blue light photoreceptor that antirepresses photosynthesis gene expression in Rhodobacter sphaeroides, Cell 110 (2002) $613-623$

[66] S. Braatsch, M. Gomelsky, S. Kuphal, G. Klug, A single flavoprotein AppA integrates both redox and light signals in Rhodobacter sphaeroides, Mol. Microbiol. 45 (3) (2002) 827-836.

[67] A.S. Steunou, C. Astier, S. Ouchane, Regulation of photosynthesis genes in Rubrivivax gelatinosus: transcription factor PpsR is involved in both negative and positive control, J. Bacteriol. 186 (2004) 3133-3142.

[68] G. Cohen-Bazire, R. Kunisawa, The fine structure of Rhodospirillum rubrum, J. Cell Biol. 16 (1963) 401-419 